\title{
Evaluation of Knowledge and Attitude toward Dental Implant Supported Prosthesis among Medical Practitioners of Wardha Region
}

\author{
Aishwary Arun Uikey ${ }^{1}$, Mithilesh M. Dhamande ${ }^{2}$, Kashish Mangal ${ }^{3}$, Anjali G. Bhoyar ${ }^{4}$, Seema R. Sathe ${ }^{5}$, Rupali M. Patel ${ }^{6}$ \\ 1,2, 3, 4, 5, 6 Department of Prosthodontics and Crown \& Bridge, Sharad Pawar Dental College and Hospital, Datta Meghe \\ Institute of Medical Sciences (Deemed to Be University), Sawangi (Meghe), Wardha, Maharashtra, India.
}

\section{ABSTRACT}

\section{BACKGROUND}

Dental knowledge of qualified medical practitioners is different when compared to the general public. Even though they are qualified in the medical field their knowledge about dental diseases, relationship of oral health with systemic diseases and life-threatening dental diseases are scarce. The role that a medical practitioner can play in improving oral health of the population depends on his own knowledge about oral diseases and their effect on general health, his attitude towards dentistry and their routine practice to maintain oral health. The purpose of this study was to assess the level of awareness regarding the use of implants in dentistry among the medical practitioners.

\section{METHODS}

Custom made questionnaire comprising of 10 closed-ended questions was designed and validated. 50 medical practitioners from different walks of medicine were randomly selected and provided with the questionnaire. Answers of all the subjects were then tabulated and subjected to statistical analysis.

\section{RESULTS}

After statistical analysis, the results obtained showed a large number of medical practitioners' negative response to maximum questions.

\section{CONCLUSIONS}

It was inferred that a huge gap in knowledge exists which needs to be addressed

\section{KEY WORDS}

Edentulism, Dental Implants, Health Care Workers
Corresponding Author: Dr. Kashish Mangal, A-62, 63, New Pali Road, Jodhpur - 342001,

Rajasthan, India.

E-mail: kashishmangal24@gmail.com

DOI: $10.14260 / \mathrm{jemds} / 2021 / 467$

How to Cite This Article:

Uikey AA, Dhamande MM, Mangal K, et al. Evaluation of knowledge and attitude toward dental implant supported prosthesis among medical practitioners of Wardha Region. J Evolution Med Dent Sci 2021;10(30):2286-2289, DOI: $10.14260 /$ jemds/2021/467

Submission 12-10-2020,

Peer Review 20-05-2020,

Acceptance 27-05-2021, Published 26-07-2021.

Copyright (C) 2021 Aishwary Arun Uikey et al. This is an open access article distributed under Creative Commons Attribution License [Attribution 4.0 International (CC $B Y 4.0)]$ 


\section{BACKGROUND}

Edentulism in any of its form, partial or complete, is known to have deleterious effect on the patient's psychology as well as his social well-being. It is often associated with disfigurement and social as well as personal unacceptance. Therefore, over the centuries, attempts in various forms have been made to provide aesthetic or functional replacement of the missing dentition. ${ }^{1,2}$ Largely accepted, advised, practiced, and popular treatment options are removable dentures or fixed prosthesis. Though with time, the cons of all such approaches have come into light. These include the technical (laboratory procedures as well as material related shortcomings) as well as clinical complications (impaired gustatory sense, feeling of heaviness in mouth, etc.). All such issues and more persuaded the researchers to discover further advanced options of replacement curbing the said disadvantages. One such developed treatment modality is dental implants.

Introduced in 1980s by Branemark, dental implants have emerged as a viable treatment option and the same has been proven by numerous literature. Undergone through multifaceted evolution, ${ }^{3}$ dental implants offer a wide array of treatment modality with substantial retention and function. Though, awareness about this frequently sought dental solution is scarce in the patient population in general, its knowledge in the medical fraternity at large is imperative. Many patients who consult a qualified medical practitioner are often in need of dental replacement. Therefore, it is valid to ascertain that the basic knowledge about dental implants, its application, benefits, and indications should exist amongst all healthcare workers. Thus, the present study was designed to assess the level of awareness and knowledge of dental implant supported prosthesis among the medical practitioners in Wardha Region.

\section{METHODS}

Institutional ethical clearance for this cross-sectional survey was obtained prior to commencement of the study (DMIMS2019/1832). To ensure a thorough survey suitable for diverse population, a custom made questionnaire was designed. Apart from assessing the practitioner's knowledge on dental implant, information on dental referrals for missing teeth by the doctor was also obtained. The self-explanatory questionnaire included closed-ended questions (Box 1). This was then thoroughly evaluated and validated by two experienced members from the Department of Assessment and Evaluation of the institution's education cell.

The list of all medical practitioners from all fields of medicine (including Ayurveda and homeopathy) was assimilated with the help of Wardha branch of various medical associations. Those having experience of at least 3 years were included in the study. Using snowball random sampling method, a sample size of 50 was derived using appropriate statistical evaluation which included healthcare workers with MBBS, BAMS, BHMS and higher qualification. All the doctors associated with either any hospital or practicing individually including the post-graduate residents were included in the study. Over a period of 3 months, the printed questionnaire was provided to all the included practitioners in person along with a verbal explanation of the purpose of the study, following which the questionnaire was filled by the doctors themselves. All the data was collected, tabulated and statistically analysed (Table 1).

\section{Statistical Analysis}

Statistical analysis was done by using descriptive statistics using frequency distribution test and software used in the analysis was SPSS 24.0 version.

\section{RESULTS}

After analysis, the authors inferred that $62 \%$ of the healthcare workers surveyed were aware that dentists deal with implant supported prosthesis whereas $28 \%$ were not. Amongst them, $66 \%$ of practitioners became aware about it from a dentist, 28 $\%$ from a friend and $6 \%$ from social media. None of the practitioners read about dental implants in newspapers. On enquiring whether the doctors were aware that dental implants in dentistry dealt with restoration of missing teeth in oral cavity, $60 \%$ of them said yes, $20 \%$ said no and $20 \%$ had no idea about it. $92 \%$ of the surveyed doctors had never come across any patient who had been rehabilitated with implant supported prosthesis whereas $8 \%$ gave positive response. When asked about referrals, only $14 \%$ had ever referred a patient with missing tooth / teeth for rehabilitation with implant supported prosthesis while $86 \%$ of the practitioners with no such referrals. $80 \%$ of the healthcare workers were not aware of the fact that intra oral prosthesis could be better supported and retained with the help of implants with only 20 $\%$ of them having this knowledge. The average cost of the implants borne by the patients was known to only $34 \%$ of the practitioners, whereas $66 \%$ were unaware.

\begin{tabular}{|c|c|c|c|c|}
\hline Question No. & Option A & Option B & Option C & Option D \\
\hline 1. Do you know that dentist deals with implant supported prosthesis? & $31(62 \%)$ & $19(38 \%)$ & & \\
\hline 2. If you have heard of it, where did you hear about it? & $0(0 \%)$ & $3(6 \%)$ & $33(66 \%)$ & $14(28 \%)$ \\
\hline $\begin{array}{l}\text { 3. Have you heard of the dental implant in dentistry which deals with the restoration of missing teeth in } \\
\text { oral cavity? }\end{array}$ & $30(60 \%)$ & $10(20 \%)$ & $10(20 \%)$ & \\
\hline $\begin{array}{l}\text { 5. Have you ever referred a patient with missing tooth/teeth for rehabilitation with implant supported } \\
\text { prosthesis? }\end{array}$ & $7(14 \%)$ & $43(86 \%)$ & & \\
\hline $\begin{array}{l}\text { 6. Are you aware of the fact that intra oral prosthesis can be better supported and retained with the help } \\
\text { of implants? }\end{array}$ & $10(20 \%)$ & $40(80 \%)$ & & \\
\hline 7. Are you aware of the average cost which the patient will have to bear for such kind of prosthesis? & $17(34 \%)$ & $33(66 \%)$ & & \\
\hline 8. What material as per your knowledge is used for fabrication of dental implants? & $13(26 \%)$ & $11(22 \%)$ & $11(22 \%)$ & $15(30 \%)$ \\
\hline $\begin{array}{l}\text { 9. Do you think this questionnaire will motivate you to refer more patients for dental implant supported } \\
\text { prosthesis rehabilitation? }\end{array}$ & $48(96 \%)$ & $2(4 \%)$ & & \\
\hline $\begin{array}{c}\text { 10. Do you think that this survey motivates you to know more about dental implant supported } \\
\text { prosthesis? }\end{array}$ & $48(96 \%)$ & $2(4 \%)$ & & \\
\hline
\end{tabular}


$30 \%$ of the surveyed doctors thought that implants were made of stainless steel, $22 \%$ of them thought that the material was either silicone or titanium and remaining $26 \%$ believed it to be acrylic resin. $96 \%$ of the practitioners were motivated to refer more patients for dental implant supported prosthetic rehabilitation whereas $4 \%$ were sceptical about it. When asked if the survey motivated them to know more about dental implant supported prosthesis, $96 \%$ responded with yes and 4 $\%$ with a no.

\section{DISCUSSION}

This study was conducted to bridge the knowledge gap amongst the medical practitioners of all medical field and the dental rehabilitation in Wardha region. The knowledge about dental implant supported prosthesis among public at large has been extensively surveyed, studied and reported by various researchers in different parts of the world throughout a wide timeline. The most common inference of such surveys, when talking specifically about those conducted amongst the Indian population, like in one conducted by Revankar et al. a huge gap between the awareness and knowledge of the patient about dental implant was found. ${ }^{4}$ All such reviews have reported that the patients being unaware, do not opt for the treatment. ${ }^{5-10} \mathrm{~A}$ huge part of this is also the fear of surgery amongst others such as the cost incurred. ${ }^{11}$ Contrary to this, there are a few reviews as well which report a relatively better percentage of population being aware about the dental implants as a prospectively promising treatment option. ${ }^{11,12}$ But it has to be noted that such population is either already a part of regular visitor of the dentists or may hail from more educated or urbane side of the society. Considering the fact that a large chunk of Indian population falls on the other side of the line, it would be apt to say that lack of awareness about the dental treatment exists. ${ }^{13}$

Even if people in general do not visit the dentist regularly, almost all of them do visit the medical practitioner for various types of ailments. These doctors can certainly play an eminent role in maintenance of the oral health of such patients by referring them to the dentist or guiding them through the procedure. Therefore, it is imperative that the healthcare workers from all walks of medicine should hold a basic knowledge as well as awareness about the role of a dentist. In general, the baseline information to maximum medical fraternity is limited to the knowledge that dentists deal with conditions related to only mouth and oral cavity, but in order to guide the patient in a proper way, it is important that they should be aware of the potential or probable dental treatment that the patient might require. In a study conducted by Nagrik et al. to evaluate awareness about various dental specialities amongst medical students as well as the teaching faculty had resulted in quite an alarming result with a significant number of their sample population being unaware of even the specialities of dentistry or the idea regarding dental specialists for specific dental problems. ${ }^{14}$ Thus, this study was undertaken to evaluate the awareness to ensure a wider reach towards the population about dental implant prosthesis.
The present study included medical practitioners from medical as well as allied sciences that is those with MBBS, BHMS or BAMS degree as the least requirement to be a part of the study. This was done to ensure that an assessment could be done undertaking various fields because there are numerous people who prefer to consult non-allopathic doctors for their conditions. Keeping this in mind, allied medical practitioners were included in the study. These doctors with a much deeper and wider approach to the population can help in guiding more patients toward a dentist regarding appropriate oral rehabilitation.

With the obtained results of this survey, following observations were made -

The awareness about a dentist's role in oral rehabilitation using implants turned out to be a common knowledge as the majority of surveyed subjects that is $62 \%$ accounting for 31 participants answered with a yes with $66 \%$ being informed so by the dentists themselves. This is in accordance with similar results in a survey conducted by Kohli et al. ${ }^{15}$ Shalya et al. ${ }^{12}$ Kaurani et al..$^{5}$ Maharjan et al. ${ }^{7}$ Prabhu et al. ${ }^{8}$ Raju et al. ${ }^{9}$ and Deeb et al. ${ }^{10}$ where the researchers reported dentists as the primary source of information about dental implants to the surveyed population. Whereas in a study conducted by Mayya et al. it was found that friends and families were the main source of information about dental implants. ${ }^{6}$ So it's an obvious lack of bridge in the communication between the dental and other medical fraternities regarding the scope of treatment options and advances there via sources which have a wider range of approach.

A significant low rate of referrals by the medical practitioners for dental implants was also noted (86\% answered no). The reason for this finding in spite of $60 \%$ of the subjects having heard about dental implants being a part of dentistry as a means of restoration in oral cavity can be attributed to unawareness regarding the basic details about it like the fact that intra oral prosthesis can be better supported by implants was not known to maximum ( $80 \%$ ) of the tested subjects and a large number of practitioners (66\%) were not aware of the cost it would incur. These unknown facts along with reduced number of encounters with dental implant rehabilitated patients ( $92 \%$ ) can account for a majority of the reason as to why there was such a low referral rate.

With this survey, we could also infer that there is a thirst for knowledge about this emerging field in dentistry among the medical practitioners from all walks of medicine as $96 \%$ of them consented to know more about this treatment modality. The results of our survey can act as motivating factors even for the various local branches of dental councils, dental associations, dental colleges or the dentists themselves to make the healthcare workers aware of dental implants as a part of public awareness programme. Such cumulative efforts can help in achieving a wider reach amongst population at large, because when people will know about it, hear about its benefits, they would understand that there are many more and better avenues for dental treatment available other than those that have been in practice for ages and generations.

The limitation of our survey was that a small sample size in a geologically specific area was surveyed. For a better understanding of the scenario and to reach larger population niche, broader land area along with higher sample size should be considered. 


\section{CONCLUSIONS}

Dental implants have now become the talk of the dental fraternity. There are hardly any dentists who would not advise it or negate its effects and benefits. It's time to take this knowledge to a more spread-out group of medical practitioners who have the ability to reach population at a much bigger level owing to their popularity amongst people or any such factor which makes them more consulted and integrated part of the society. This study surely displays the disparity existing between the awareness about dental implants within medical practitioners of Wardha region. Not only this, but also a difference amongst the perception of implant's role, its functionality and costing existed. Our survey also helped in highlighting that the thirst for knowledge about dental implants existed in other medical branches as maximum of the participants said that they wanted to know more about dental implants after the survey. Thus, it can help to motivate people to address this gap of knowledge and help us as health workers to stand more true on our promise to serve the society to the best of our abilities.

Data sharing statement provided by the authors is available with the full text of this article at jemds.com.

Financial or other competing interests: None.

Disclosure forms provided by the authors are available with the full text of this article at jemds.com.

\section{REFERENCES}

[1] Mysore AR, Aras MA. Understanding the psychology of geriatric edentulous patients: understanding the psychology of geriatric edentulous patients. Gerodontology 2012;29(2):e23-7.

[2] Emami E, De Souza RF, Kabawat M, et al. The impact of edentulism on oral and general health. Int J Dent 2013;2013:498305.

[3] Rajput R, Chouhan Z, Sindhu M, et al. A brief chronological review of dental implant history. Int Dent J Stud Res 2016;4(3):105-7.

[4] Revankar RP, Sathe S, Borle AB, et al. Evaluation of knowledge, attitude and awareness of patients regarding dental implants in Central India. Int J Dent Sci Innov Res 2019;2(3):285-91.

[5] Kaurani P, Kaurani M. Awareness of dental implants as a treatment modality amongst people residing in Jaipur (Rajasthan). J Clin Diagn Res 2010;4(6):3622-6.

[6] Mayya A, D'Souza J, George A, et al. Knowledge and awareness of dental implants as a treatment choice in adult population in South India: a hospital-based study. Indian J Dent Res 2018;29(3):263-7.

[7] Maharjan A, Regmi S, Sagtani RA. Knowledge and awareness regarding dental implants among patients attending a tertiary care center. JNMA J Nepal Med Assoc 2018;56(210):578-81.

[8] Prabhu A, Mundathaje M. Knowledge, attitude and awareness of patients regarding dental implants: a crosssectional study. J Int Oral Health 2018;10(6):278-82.

[9] Raju CM, Gunupati S, Babu MM, et al. Patients' awareness toward implant-supported prosthesis: an observational study. J Contemp Dent Pract 2017;18(1):49-51.

[10] Deeb G, Wheeler B, Jones M, et al. Public and patient knowledge about dental implants. J Oral Maxillofac Surg 2017;75(7):1387-91.

[11] Siddique E, Bhat P, Kulkarni S, et al. Public awareness, knowledge, attitude and acceptance of dental implants as a treatment modality among patients visiting SDM College of dental sciences and hospital, Dharwad. J Indian Soc Periodontol 2019;23(1):58-63.

[12] Shalya R, Reddy PVN, Rani KR, et al. Assessment of public awareness towards dental implants using web based survey technique. Galore Int J Health Sci Res 2020;5(1):3845.

[13] Sathe S, Kambala R, Dubey S, et al. Awareness and perception of sample rural indian population towards denture marking. Int J Contemp Med Res 2018;5(4):D31-3.

[14] Nagrik A, Bhagat B, Yemle S, et al. Awareness of specialties of dentistry among medical trainees and teaching faculty of medical college in the central West India. J Int Soc Prev Community Dent 2019;9(3):269-74.

[15] Kohli S, Bhatia S, Kaur A, et al. Patients awareness and attitude towards dental implants. Indian J Dent 2015;6(4):167-71. 